\title{
Gel-combustion-synthesized ZnO nanoparticles for visible light-assisted photocatalytic hydrogen generation
}

\author{
ALAMELU K RAMASAMI ${ }^{1}$, T N RAVISHANKAR ${ }^{1,2}$, G NAGARAJU ${ }^{1,3}$, T RAMAKRISHNAPPA ${ }^{1,4}$, \\ SERGIO RIBEIRO TEIXEIRA ${ }^{2}$ and R GEETHA BALAKRISHNA ${ }^{1, *}$ \\ ${ }^{1}$ Centre for Nano and Material Sciences, Jain University, Jain Global Campus, Bangalore 562112, India \\ ${ }^{2}$ Laboratory of Thin Films and Nanostructure Fabrication (L3F nano) Institute of Physics, Universidade Federal do Rio \\ Grande do Sul, Avenida Bento Gonçalves, Post Box 9500, Porto Alegre 91.501-970, Brazil \\ ${ }^{3}$ Department of Chemistry, Siddaganga Institute of Technology, Tumkur 572103, India \\ ${ }^{4}$ Department of Chemistry, Dayananda Sagar Academy of Technology and Management, Udayapura, \\ Bangalore 560082, India
}

MS received 5 April 2016; accepted 2 July 2016

\begin{abstract}
Zinc oxide nanoparticles (ZnO NPs) synthesized by the gel combustion technique using a bio-fuel, cassava starch (root tubers of Manihot esculenta), have been characterized by various techniques. The $\mathrm{X}$-ray diffraction pattern reveals hexagonal wurtzite structure. The particle size averaged around $\mathbf{4 5} \mathrm{nm}$ with an excellent band gap of $2.5 \mathrm{eV}$. The scanning electron and transmission electron microscopic images confirm the ZnO NPs to be agglomerated with loop- and chain-like morphology. The ZnO NPs prepared by this method is a promising candidate for photocatalytic hydrogen generation $\left(41 \mu \mathrm{mol} \mathrm{h}{ }^{-1} \mathrm{~g}^{-1}\right)$ under $\mathrm{UV}$ light illumination and $\left(140 \mu \mathrm{mol} \mathrm{h}-1 \mathrm{~g}^{-1}\right) \mathrm{under}^{-1}$ visible light illumination.
\end{abstract}

Keywords. ZnO nanoparticles; gel combustion; cassava starch; hydrogen generation; visible light.

\section{Introduction}

$\mathrm{ZnO}$ has been studied since 1935 [1], yet the application of this material is far-reaching and ever expanding. The various semiconductor applications of $\mathrm{ZnO}$ can be attributed to its large exciton binding energy, $60 \mathrm{meV}$ [2] at room temperature, and direct, wide band gap [3]. The varied applications are photocatalytic degradation [4], photodetection [5], solar cell application [6] and sensing [7]. Due to the wide range of applications, numerous methods are available for the synthesis of $\mathrm{ZnO}$ nanomaterials. As solution method offers a simple and environment-friendly route, more emphasis is laid on this strategy. A few examples of solution method are hydrothermal [8], sol-gel [9], microwave-assisted synthesis [10] and solution combustion synthesis [7]. Recently the use of 'green' fuels and technology has been gaining prominence. Singh et al [11] have used madder plant for the preparation of $\mathrm{ZnO}$ at room temperature. Ramimoghadam et al $[8,12]$ have used rice and palm olein as a biotemplate for the growth of $\mathrm{ZnO}$ nanoparticles (ZnO NPs). Zhang et al [13] and Taubert and Wegner [14] have prepared $\mathrm{ZnO}$ nanostructures from soluble starch. Gel combustion synthesis of nanoparticles has also been attempted by different researchers $[15,16]$. It is the rapid ignition of a homogeneous solution of oxidizer, usually metal nitrates, and organic fuel to produce metal oxide nanomaterials. Taking a lead from the abovementioned methods, gel combustion technique using cassava

\footnotetext{
*Author for correspondence (br.geetha@jainuniversity.ac.in)
}

starch as a fuel has been attempted by our group. The advantages of this method are the following: it is rapid, simple, cost-effective and fine crystals of the product are formed within $10 \mathrm{~min}$ that require no further treatment [17]. The basic pre-requisite condition in both solution and gel combustion processes is that the precursors should form a homogeneous solution. In this process that we have adopted, the processed starch was insoluble in water even at elevated temperature and this, to the best of our knowledge, has not been attempted so far. This, indeed, is an additional advantage along with the others like ease of availability, low cost and simple preparation procedure of the cassava starch. In any combustion process involving starch, the carbohydrate content decides the efficiency of the reaction. Cassava (Manihot esculenta, Euphorbiaceae family), like potato, is a root tuber where starch [18] is stored in the roots. It is the major staple diet in Africa [19], consumed by 500 million people around the world [20] and is the sixth major crop of the world [21]. Cassava was preferred to the other starch-rich crops (corn and potato) because of its improved starch content [22].

Energy is the bone of contention all over the world today as the fossil fuels are fast depleting. Scientists are on the lookout for environmentally benign sources to dissipate the mounting pollution hazards. Keeping in view the non-hazardous nature, abundance in water and bio-mass and high energy yield $\left(122 \mathrm{~kJ} \mathrm{~g}^{-1}\right)$, hydrogen has become the fuel for the future [23]. Hydrogen has been mostly produced by thermochemical splitting of water by a photocatalyst as reported by many researchers [24,25]. Thermochemical 
water splitting by $\mathrm{ZnO}$ involves $\mathrm{ZnO} / \mathrm{Zn}$ redox mechanism where the conversion of $\mathrm{ZnO}$ to $\mathrm{Zn}$ is an energy-demanding process. Photocatalytic hydrogen generation based on semiconductors, on the other hand, is a viable and an easy option to produce this clean energy. Since the discovery of water splitting by Fujishima and Honda [26], metal oxide semiconductors (in hydrogen generation) have come a long way. Though much research has been devoted to $\mathrm{TiO}_{2}[27,28]$, doped $\mathrm{TiO}_{2}$ [29] and $\mathrm{TiO}_{2}$ nanocomposites [30], very few reports are available for $\mathrm{ZnO}$ [31] to produce hydrogen photocatalytically. Wang and Yao [32] have used $\mathrm{ZnO}$ rodCdS/reduced graphene oxide and Peng et al [33] have used Pt-loaded $\mathrm{ZnO}$. To the best of the authors' knowledge, this is the first report on the visible light-assisted photocatalytic hydrogen generation from bare $\mathrm{ZnO}$. This $\mathrm{ZnO}$ has been synthesized by simple gel combustion using a novel bio-fuel.

\section{Experimental}

\subsection{Preparation of cassava starch}

Cassava starch was prepared according to our earlier report [4]. In brief, the cassava pearls procured from the local market were hand-picked to remove bulk impurities, washed with tap water and rinsed with distilled water to remove dust contamination. Purified cassava pearls $(500 \mathrm{~g})$ were taken in a beaker, known volume of water was added and it was heated on a hot plate at $150^{\circ} \mathrm{C}$ for almost $1 \mathrm{~h}$ till the pearls became glassy and transparent. This viscous gel was transferred to a clean plastic sheet, covered with a thin cloth (to prevent dust contamination) and dried in sunlight (where retrogradation and syneresis occur) for a week till it became brittle. It was then powdered and stored in air-tight containers to prevent dust contamination and was termed cassava starch.

\subsection{Preparation of $\mathrm{ZnO} \mathrm{NPs}$}

Zinc nitrate hexahydrate (Merck, India) and cassava starch in 1:0.5 ratio were taken; $1: 1$ and 1:0.25 ratios were tried and 1:0.5 was found to give the best result, based on our earlier work [4] and has been used in this present work. They were mixed well with $30 \mathrm{ml}$ water (not a homogeneous solution but a suspension) and heated on a hot plate at $200^{\circ} \mathrm{C}$ till it formed a viscous gel. The gel was introduced into a muffle furnace at around $475^{\circ} \mathrm{C}$, where the combustion reaction occurred within $5 \mathrm{~min}$ with the evolution of gases like $\mathrm{NO}_{2}, \mathrm{CO}_{2}$ and water vapour. The self-propagating heat wave resulting in a smouldering type of reaction occurred with a flaky, voluminous product formation. The product was calcined at $500^{\circ} \mathrm{C}$ for $5 \mathrm{~h}$ to remove the impurities.

\subsection{Characterization}

The structure of the synthesized $\mathrm{ZnO}$ NPs was determined using a Philips X'pert PRO X-ray diffractometer with graphite monochromatized $\mathrm{Cu}-\mathrm{K} \alpha(1541 \AA)$ radiation. The
Fourier transform infrared spectrum of the sample was recorded using a Bruker Alpha-P spectrometer. The absorption spectra of the samples were measured using a Shimadzu UV 1650 PC UV-visible spectrometer. Raman spectra were recorded at several different spots in backscattering geometry using $514.5 \mathrm{~nm} \mathrm{Ar}^{+}$laser in a HORIBA LabRam HR800 spectrometer. Photoluminescence (PL) measurement was done using a Shimadzu spectrofluorimeter (model RF $5301 \mathrm{PC}$ ) at $325 \mathrm{~nm}$ excitation. The morphology of the product was analysed using a Carl Zeiss Ultra 55 scanning electron mirosope (SEM) and Technai G2 F30 transmission electron mirosope (TEM). X-ray photoelectron spectroscopy (XPS), recorded with a $\mathrm{Mg}-\mathrm{K} \alpha(1253.6 \mathrm{eV}) \mathrm{X}$-ray source, was used to determine the composition of the sample. The C $1 \mathrm{~s}$ peak at $284.6 \mathrm{eV}$ was used for the binding energy calibrations.

\subsection{Photocatalytic hydrogen generation}

Photocatalytic $\mathrm{H}_{2}$ production reactions were carried out in a closed gas-circulating system as depicted in figure 1 . The photocatalyst $(8 \mathrm{mg}$ ) was sonicated in $7.5 \mathrm{ml}$ water $(20 \mathrm{~min})$ for uniform dispersion. After sonication, $2.5 \mathrm{ml} \mathrm{(25 \textrm {vol } \% )}$ ethanol was added as a sacrificial reagent. A $240 \mathrm{~W} \mathrm{Hg}-\mathrm{Xe}$ arc lamp (Cermax) was used as the UV excitation source, a $300 \mathrm{~W}$ Xe arc lamp, with the incident photon flux $I_{0}$ of 0.056176 or $0.078245 \mu \mathrm{mol} \mathrm{cm}{ }^{-2} \mathrm{~s}^{-1}$, was focused through a shutter window and a 420 or $390 \mathrm{~nm}$ cut-off filter onto the window face of the cell was used as the visible light source. Prior to the reaction, the mixture was deaerated by purging Ar gas repeatedly to minimize the oxygen content. The liberated $\mathrm{H}_{2}$ was periodically analysed using an Agilent 6820 GC chromatograph equipped with a thermal conductivity detector and a $5 \AA$ molecular sieve-packed column with argon as the carrier gas. Using a gas-tight syringe $(50 \mathrm{ml})$ the amount of $\mathrm{H}_{2}$ produced was measured at $0.5 \mathrm{~h}$ time interval. The amount of gas liberated is plotted as a function of light exposure time. During the entire experiment, the reaction temperature was maintained at $25^{\circ} \mathrm{C}$ by eliminating the IR radiation with the circulation of water in the water jacket of the reactor.

\section{Results and discussion}

\subsection{Interaction of the fuel and precursor}

In this method, cassava starch has three types of roles to play; a fuel to propagate the combustion, a bio-template and nuclei seeding the nanoparticle growth and a surfactant that decreases the surface tension, allowing the particles to escape the aggregation process and thereby, limiting the particle size [34]. All the three roles take effect when cassava starch is heated beyond its gelatinization temperature, $65^{\circ} \mathrm{C}$ [35]. After this point the hydrogen bonds in the carbohydrates break and the liberated hydroxyl groups associated with the water molecules cause the starch to swell and prompt the nanoparticle growth. After nanoparticles begin to 


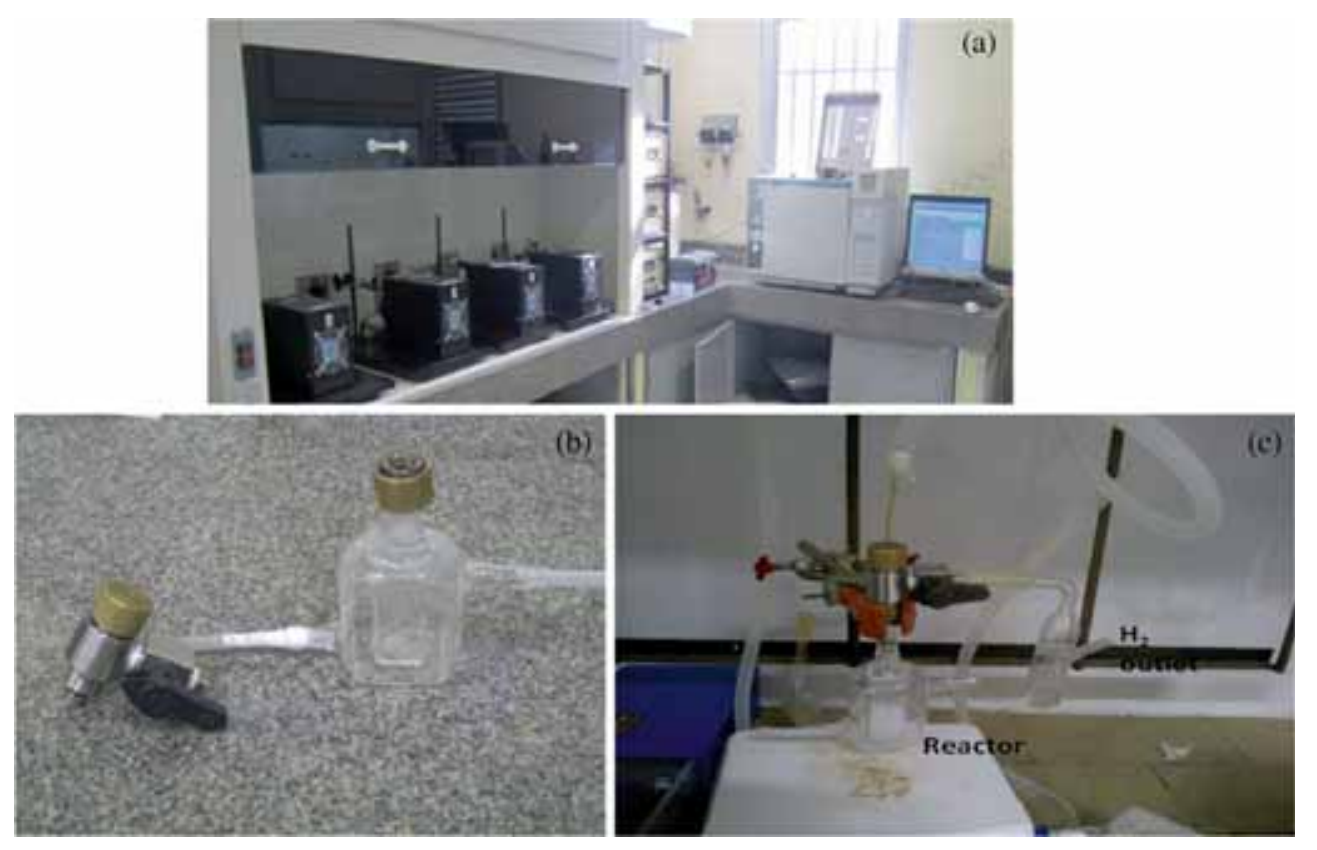

Figure 1. Experimental set-up picture of photocatalytic hydrogen generation.

grow the starch begins to behave like a surfactant and prevents agglomeration and reduces the particle size. Later on as the temperature increases, the starch functions as a fuel supporting the combustion process.

\subsection{Diffraction studies}

X-ray diffraction peaks revealed the ZnO NPs with hexagonal wurtzite symmetry corresponding to zinc oxide (JCPDS No. 76-704) as depicted in figure 2. The absence of additional peaks indicates phase purity and sharp peaks indicate crystallinity. The lattice parameters are $a=b=3.253 \AA$ and $c=5.213 \AA$ and the space group is P63mc. The particle size as calculated by Scherer's formula (equation (1)) was found to be $33 \mathrm{~nm}$ :

$$
D=\frac{K \lambda}{\beta \cos \theta},
$$

where $D$ is the crystallite size, $K$ is Scherrer's constant (0.9 for spherical particles), $\lambda$ is the wavelength of the X-rays used, $\beta$ is line broadening at half maximum intensity or the full-width at half-maximum (FWHM) and $\theta$ is Bragg's angle.

The $c / a$ for an ideal hexagonal system is 1.633 . The $c / a$ for $\mathrm{ZnO}$ NPs (1.603) indicate a distorted hexagonal system arising out of the high temperature employed for calcination [31]. The particle size as calculated by the Williamson-Hall (W-H) equation [36] was $52 \mathrm{~nm}$. The $\mathrm{W}-\mathrm{H}$ approach takes into account the stress and strain in the sample and is given as follows:

$$
\beta_{\text {total }}=\beta_{\text {size }}+\beta_{\text {strain }}=\frac{0.891 \lambda}{D \cos \theta}+4 \varepsilon \sin \theta .
$$

The calculation of crystallite size in $\mathrm{W}-\mathrm{H}$ method consists of plotting $4 \sin \theta$ against $\beta \cos \theta$ as in supplementary figure $\mathrm{S} 1$,

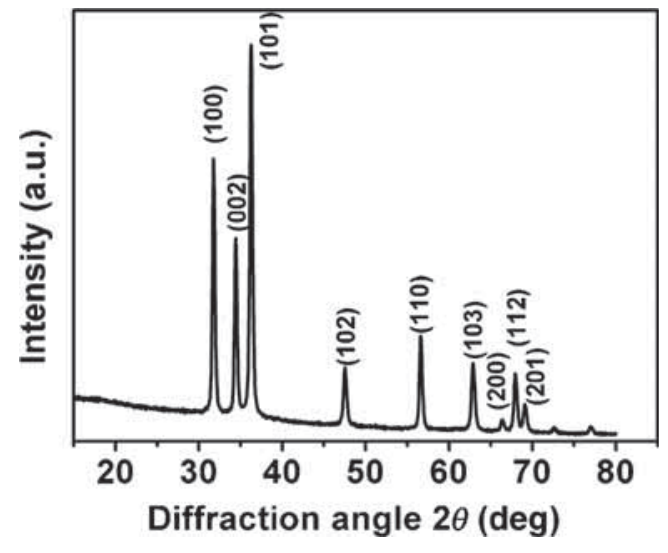

Figure 2. X-ray diffraction pattern of $\mathrm{ZnO}$ NPs.

where the intercept (of the $y$-axis) is the crystallite size and the slope is $\varepsilon$, the strain. A positive slope in the plot is indicative of strain broadening [36], suggesting a lattice expansion that is well augmented by lattice parameters. The difference arising in the crystal size calculated by Scherrer's equation and W-H plot is an additional indication of appreciable strain in the sample. The reported lattice parameter values for bulk $\mathrm{ZnO}$ are $a=b=3.249 \AA$ and $c=5.205 \AA$.

If the lattice parameter $c$ is greater than that of the bulk, as in the present study, the crystal experiences extensive stress [37]. The extensive stress resulted in increased volume of the unit cell as compared to the bulk. The variation in lattice parameters can be explained based on defect concentration. When $\mathrm{ZnO}$ is calcined in oxygen-rich atmosphere (provided by the burning fuel during synthesis), interstitial oxygen is formed, which is confirmed by a small peak at $1117 \mathrm{~cm}^{-1}$ in FTIR [38]. This interstitial oxygen binds to the lattice oxygen 
forming substitutional oxygen molecule [39]. This results in a slight outward movement of the $\mathrm{Zn}$ atoms that are close by with a consequential increase in lattice parameter and volume [40].

\subsection{Vibrational spectral studies}

3.3a Fourier transform infra-red spectral (FTIR) studies: The FTIR spectrum of ZnO NPs from 4000 to $250 \mathrm{~cm}^{-1}$ is depicted in figure $3 \mathrm{a}$. The broad band over $3400-3600 \mathrm{~cm}^{-1}$ is due to $\mathrm{OH}$ stretching/Zn-OH- $\mathrm{Zn}$ bond. The peaks in the range of $2000-2200 \mathrm{~cm}^{-1}$ are due to $\mathrm{CO}$ adsorbed on the surface. The peaks occurring in $1400-1750 \mathrm{~cm}^{-1}$ region indicate $-\mathrm{OH}$ bending of the adsorbed moisture on the sample [41]. The FTIR spectrum of ZnO NPs from 1200 to $250 \mathrm{~cm}^{-1}$ is shown in figure $3 b$. The peak at around $1100 \mathrm{~cm}^{-1}$ indicates interstitial oxygen [38]. The occurrence of interstitial oxygen and its influence on the lattice has been discussed at length elsewhere in the article. Peaks in the range 900$1200 \mathrm{~cm}^{-1}$ indicate $\mathrm{Zn}-\mathrm{O}-\mathrm{Zn}$ bonding. Similarly peaks in $780-980 \mathrm{~cm}^{-1}$ region might be due to peroxide ( $\mathrm{Zn}-\mathrm{O}-\mathrm{O}-$ $\mathrm{Zn})$ formation. The main absorption peaks of $\mathrm{ZnO}$ occur at 398 and $511 \mathrm{~cm}^{-1}$ due to stretching vibration of $\mathrm{Zn}-\mathrm{O}$ [41].

3.3b Raman spectral studies: Raman spectroscopy is an important tool to study the crystal quality and the vibrations occuring due to defects. Hexagonal $\mathrm{ZnO}$ has $\mathrm{A}_{1}, \mathrm{E}_{1}$ Raman active modes and $\mathrm{B}_{1}$ Raman inactive mode. The Raman
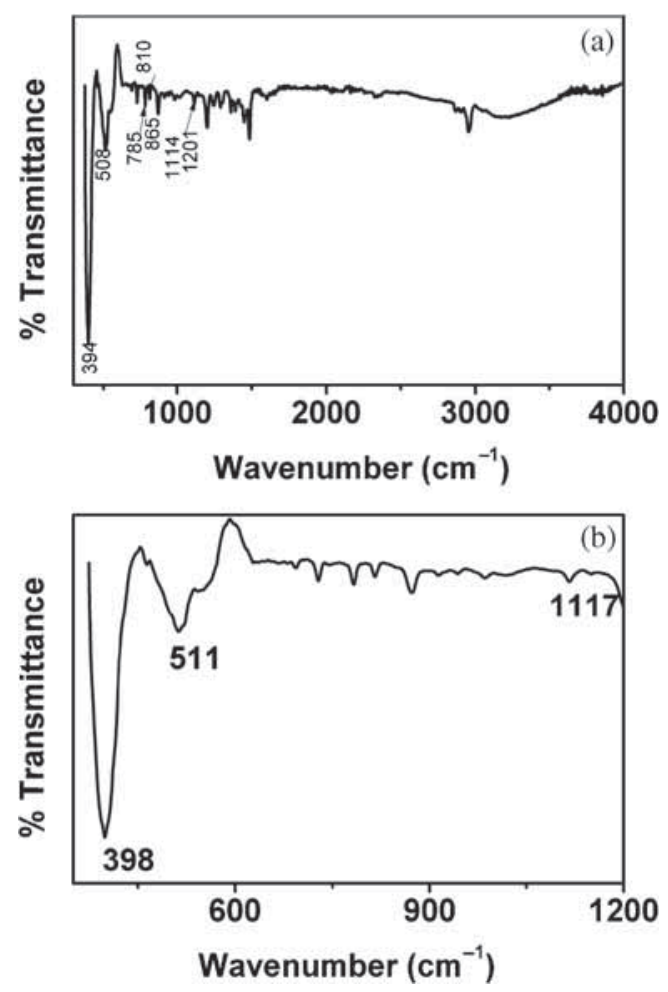

Figure 3. FTIR spectrum of $\mathrm{ZnO}$ NPs. spectrum is shown in figure 4 . The sharp and intense peak at $440 \mathrm{~cm}^{-1}$ indicates non-polar E2(H) phonon vibration mode of oxygen sub-lattice and the peak at $333 \mathrm{~cm}^{-1}$ is attributed to $\mathrm{E} 2(\mathrm{H})-\mathrm{E} 2(\mathrm{~L})$ multiphonon vibration. The first and second order modes of $A_{1}$ are located at 519 and $1156 \mathrm{~cm}^{-1}$, respectively [42]. The Raman spectrum indicates the absence of carbon in the sample, though peaks corresponding to $\mathrm{CO}$ were present in the FTIR spectrum, indicating that the peaks could be due to the interference from the surroundings.

\subsection{Optical spectral studies}

The UV-visible spectrum of ZnO NPs is shown in figure 5. The peak at $373 \mathrm{~nm}$ can be assigned to intrinsic band gap absorption of $\mathrm{ZnO}$ due to electronic transition from the valence band to conduction band $\left(\mathrm{O}_{2 \mathrm{p}} \rightarrow \mathrm{Zn}_{3 \mathrm{~d}}\right)$ [43]. The sharp peak denotes that the particles are in nanodimension and the size distribution is narrow [44]. A note-worthy aspect of the spectrum is a long absorption tail stretching into the visible region indicating a significant absorption range near the inter-band transition region due to oxygen excess defects [45], making it sunlight active. This is called the band tailing effect. A detailed explanation of this effect is discussed elsewhere in the article. The optical band gap

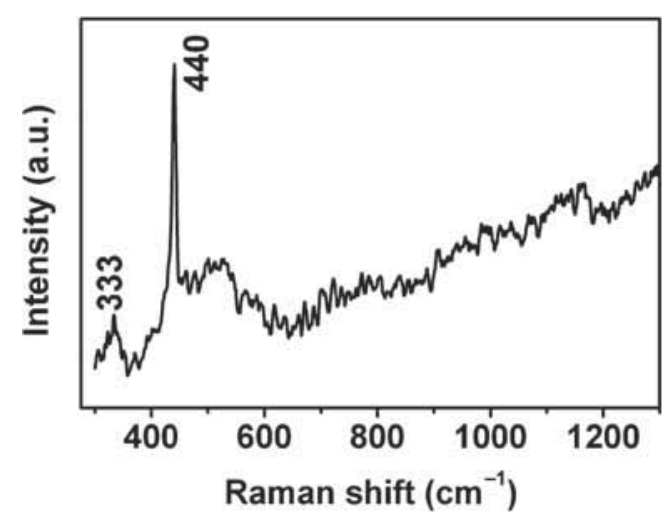

Figure 4. Raman spectrum of $\mathrm{ZnO}$ NPs.

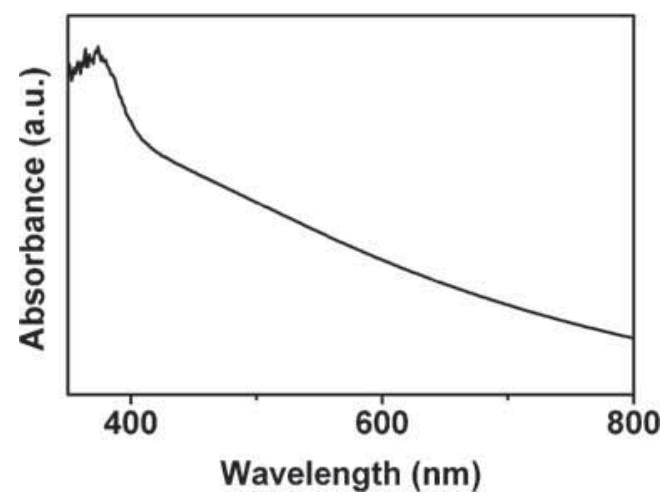

Figure 5. UV-visible spectrum of $\mathrm{ZnO}$ NPs. 


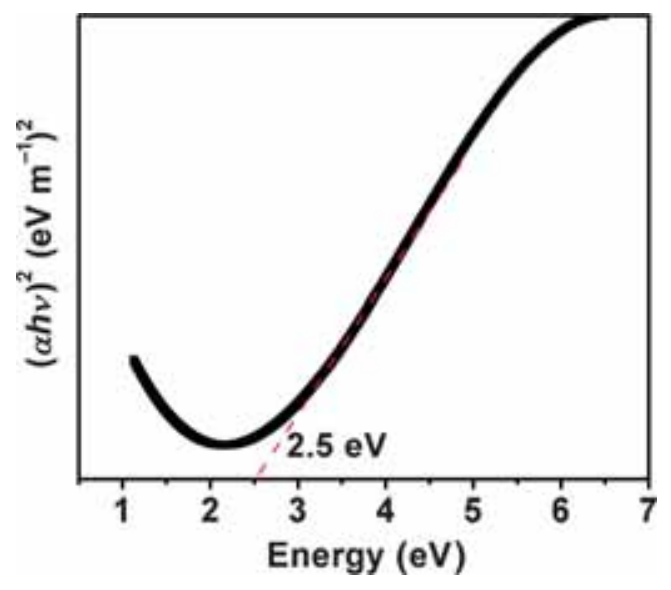

Figure 6. Band gap plot of $\mathrm{ZnO}$ NPs.

measurements made from the absorption maximum usually give misleading and erroneous results. The band gap value calculated based on the Kubelka-Munk plot in figure 6 was found to be $2.5 \mathrm{eV}$. Since the $\mathrm{ZnO}$ NPs' size is very much greater than the Bohr exciton radius, the apparent blue-shift and the reduced particle size $(45 \mathrm{~nm})$ can be credited to the fuel rather than quantum confinement [46]. The band gap reduction in semiconductors can happen by way of doping [47-49] or fast crystallization process like microwave irradiation [50]. However, in the present study the band gap reduction happened in an undoped semiconductor prepared by combustion reaction. The possible reasons behind band gap reduction are (1) lattice parameter variation and (2) valence band modification due to oxygen excess defects [40]. Lattice parameter is an important factor affecting the band gap and decreases in band gap values are observed with increase in lattice parameters for III-V semiconductors [51]. Hence, in this present work, the interstitial oxygen excess defects interact with lattice oxygen atoms, resulting in increased lattice parameters and reduced band gap $[39,52]$. To investigate the change in band gap values due to the presence of defects, Urbach energy or band tail energy is also considered. The Urbach tail, defined as the width of the localized states, created by defects in the optical band gap affects the band gaps, structure and optical transitions [53]. The amount of tailing is determined by the following equation [54]:

$$
\alpha=\alpha_{0} \exp \left(\frac{E}{E_{\mathrm{U}}}\right)
$$

where $\alpha$ is absorption coefficient, $\alpha_{0}$ is a constant, $E$ is photon energy and $E_{\mathrm{U}}$ is the Urbach energy or width of the exponential absorption edge.

Figure 7 shows the variation of photon energy vs. $\ln (\alpha)$. $E_{\mathrm{U}}$ is calculated from the reciprocal of slope and is found to be $1.24 \mathrm{eV}$. The band gap is inversely related to $E_{\mathrm{U}}$. Hence, higher the $E_{\mathrm{U}}$ value, more the band tailing between valence and conduction band; consequently, lesser the band gap. In other words, the excited electron prefers to transit from valence band to band tailing resulting in the reduction of band gap of $\mathrm{ZnO}$ NPs [55].

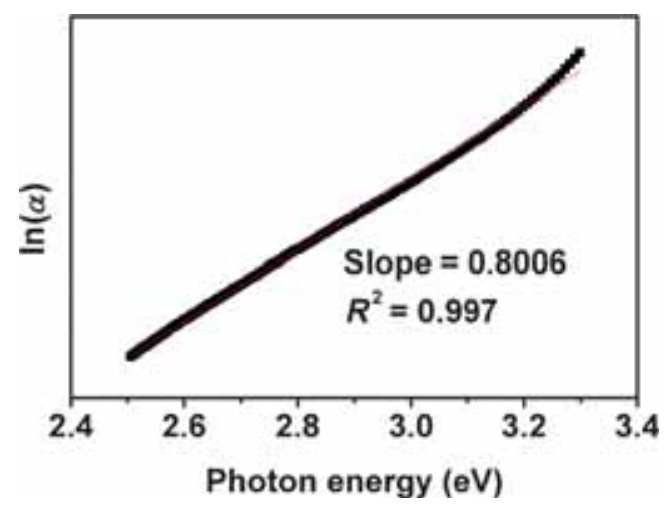

Figure 7. Urbach energy plot.
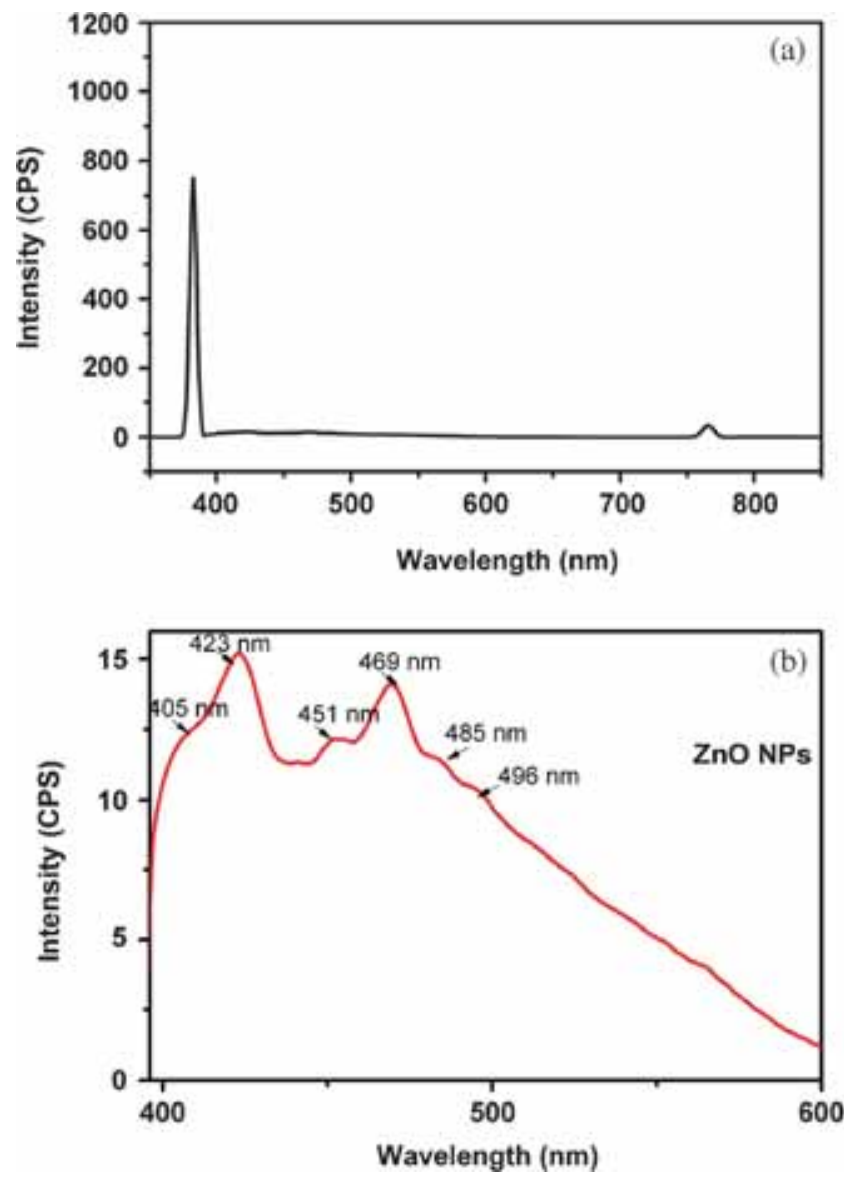

Figure 8. Photoluminescence spectra of $\mathrm{ZnO}$ NPs.

\subsection{PL spectral studies}

The PL spectra of ZnO NPs are depicted in figure 8. The physical properties of metal oxide nanostructures are closely linked to the density of their defects and PL spectrum elucidates this structure-property relationship [56]. The PL spectrum of $\mathrm{ZnO}$ mainly consists of two bands: near-band-edge emission (NBE) and defect-related deep (DLE) and shallow 
(SLE) level emissions in the visible region [57]. The native (intrinsic) defects that occur in $\mathrm{ZnO}$ are oxygen vacancies $\left(\mathrm{V}_{\mathrm{O}}^{\bullet}\right.$, singly ionized and $\mathrm{V}_{\mathrm{O}}^{\bullet}$, doubly ionized), zinc vacancies $\left(\mathrm{V}_{\mathrm{Zn}}\right)$ and oxygen interstitials $\left(\mathrm{O}_{\mathrm{i}}\right)$ [58]. The origin of these defects is ambiguous and different theories have been proposed to explain them [59]. To evaluate the concentration of structural defects, UV emission at NBE is compared to DLE and SLE. The relatively lesser DLE (green emission) as seen in figure 8a accounts for lesser structural defects in the $\mathrm{ZnO}$ lattice. The near-absence of green emission and a small FWHM $(60 \mathrm{meV})$ of the NBE indicate that the concentration of defects (that are responsible for DLE) is negligible [60]. The band at around $390 \mathrm{~nm}$ indicates the recombination of electrons and holes at the conduction band (CB) edge. The $510 \mathrm{~nm}$ emission (due to $\mathrm{V}_{\mathrm{O}}^{\bullet}$ capturing an electron) and $660 \mathrm{~nm}$ emission (due to interstitial $\mathrm{Zn}$ ion) are conspicuously absent, as seen in figure 8a [61], implying the nonexistence of these two defects. The $510 \mathrm{~nm}$ green luminescence is responsible for degradation of optical properties in $\mathrm{ZnO}$ and by its characteristic absence it is understood that $\mathrm{ZnO}$ NPs can be favourably considered for optical applications [62]. The peaks at 498 and $485 \mathrm{~nm}$ in $\mathrm{ZnO}$ NPs, as observed in figure $8 \mathrm{~b}$, may be due to green DLE from CB to antisite oxygen occurring near valance band (VB) [63]. Nevertheless, the area under these peaks is very less compared with the entire PL spectrum, indicating the existence of only a small fraction of these defects in ZnO NPs. Oxygen vacancies are intrinsic defects in the $\mathrm{ZnO}$ lattice having two energy levels in the forbidden gap. They are the 510 and $469 \mathrm{~nm}$ emission due to $\mathrm{V}_{\mathrm{O}}^{\bullet}$ and $\mathrm{V}_{\mathrm{O}}^{\bullet \bullet}$, respectively. In the aforementioned discussion the absence of $\mathrm{V}_{\mathrm{O}}^{\bullet}$ has been elaborated. $\mathrm{V}_{\mathrm{O}}^{\bullet \bullet}$ does not capture electrons; in other words, it is not a recombination centre; hence it will not affect the photocatalytic activity [62]. The peaks at 451 and $423 \mathrm{~nm}$ are due to SLE from $V_{Z n}$ occurring near $C B$ to VB [63]. The point defects of $\mathrm{ZnO}$ lattice were analysed using first principles pseudopotential method by Kohan et al [64]. It has been recorded by them that under oxygen-rich conditions the energy difference between $\mathrm{CB}$ and $\mathrm{V}_{\mathrm{Zn}}$ equals $2.6 \mathrm{eV}$, which is almost close to that of the KM plot in figure 6. The oxygen-rich atmosphere, in the present study, is provided by the fuel during the combustion process. This is an additional proof of the existence of oxygen excess defect apart from those indicated by diffraction and vibration spectral studies. Kohan et al [64] had predicted, based on their calculation, that the emission due to $\mathrm{V}_{\mathrm{Zn}}$ must occur at around $476 \mathrm{~nm}$. But $\mathrm{V}_{\mathrm{Zn}}$ emission of $\mathrm{ZnO}$ NPs was found to be at $405 \mathrm{~nm}$. This was recorded by other researchers too $[63,65]$. The reason behind this blueshift is that $\mathrm{V}_{\mathrm{Zn}}$ reacts with oxygen to form oxygen antisites $\mathrm{O}_{\mathrm{Zn}}$ under oxidative conditions as given in equation (4) [62]:

$$
\frac{1}{2} \mathrm{O}_{2}+\mathrm{V}_{\mathrm{Zn}}=\mathrm{O}_{\mathrm{Zn}}
$$

This further confirms the oxidative environment in the synthesis procedure. The band at $390 \mathrm{~nm}$ (NBE) is mainly linked to recombination of photoexcited electrons and holes than to native point defects in $\mathrm{ZnO}$ lattice. The reduced intensity of this peak in ZnO NPs as observed from figure 8a suggests lesser recombination probability and improved separation of charge carriers [66]. Moreover, the excess oxygen present can also act as electron scavengers, leading to reduced luminescence [67]. The peak at around $760 \mathrm{~nm}$ is due to the second order peak of $\mathrm{ZnO}$ corresponding to NBE [68]. Thus, based on PL spectrum of $\mathrm{ZnO}$ NPs, it can be concluded that there are lesser native defects that make it a potential photocatalyst. Etacheri et al [69] have documented that the reduced $\mathrm{NBE}$ and excitonic emissions in $\mathrm{Mg}$-doped $\mathrm{ZnO}$ account for enhanced photocatalytic activity in the degradation of dyes. This phenomenal behaviour is uncommon in bare/undoped metal oxides though frequently reported in doped oxides. The degradation of dyes and hydrogen generation are two different processes but both work on the same mechanism. This behavoiur of undoped $\mathrm{ZnO}$, to the best of the authors' knowledge, is the first one to be reported and has been well exploited in photocatalytic hydrogen generation. Interestingly, highly crystalline and less defective semiconductors are best suited for hydrogen generation [70], making ZnO NPs a promising photocatalyst.

\subsection{Quantum yield}

The fluorescence quantum yield (QY) is an important parameter to determine the efficiency of emission process, which is defined as the ratio of number of emitted photons to the number of absorbed photons per unit time. The unknown relative QY is compared to that of a reference (here, qunine sulphate) and is given by the equation

$$
Q_{x}=\frac{Q_{R} *(\text { slope })_{x} * \eta_{x}^{2}}{(\text { slope })_{R} * \eta_{R}^{2}} .
$$

$Q$ is the QY ( $x$ is the sample and $R$ is the reference) and $\eta$ is the refractive index of the solvent (ethanol) [71]. The slope is calculated by plotting absorbance against integrated fluorescence intensity (the area of fluorescence spectrum). Absorbance vs. fluorescence intensity of quinine sulphate and $\mathrm{ZnO}$ NPs is depicted in figure $9 \mathrm{a}$ and $\mathrm{b}$, respectively. The QY calculated according to equation (4) is 0.122 .

\subsection{Morphology studies}

The scanning and transmission electron micrographs of $\mathrm{ZnO}$ NPs are shown in figure 10. The images reveal cluster of chains and loops of nanopaprticles. The particle size calculated based on the TEM was found to be $45 \mathrm{~nm}$ and TEM image complements the morphology as revealed by the SEM. It has been demonstrated that particles in the size range of 50-70 nm exhibit better photocatalytic activity [72]. TEM images also support the findings obtained using the SEM, where the particles are slightly aggregated to form loops and chains, which help in the transfer of photogenerated electrons and holes to the surface and preventing their recombination in the bulk [73], thereby enhancing photocatalytic activity. 


\section{$3.8 X$-ray photoelectron spectroscopic (XPS) studies}

The XPS spectrum was recorded to study the chemical bond and oxidation state of the elements present. It revealed the presence of $\mathrm{Zn}$ and $\mathrm{O}$. The wide spectrum of $\mathrm{ZnO}$ and highresolution individual spectra of $\mathrm{O} 1 \mathrm{~s}$ and $\mathrm{Zn} 2 \mathrm{p}$ are depicted in figure 11a, b and c, respectively. The two strong peaks with binding energies 1022 and $1045 \mathrm{eV}$ are due to $\mathrm{Zn} 2 \mathrm{p}_{3 / 2}$ (corresponding to the attachment of hydroxyl groups to zinc ions on the surface) and $\mathrm{Zn} 2 \mathrm{p}_{1 / 2}$ (corresponding to $\mathrm{Zn}$ atoms
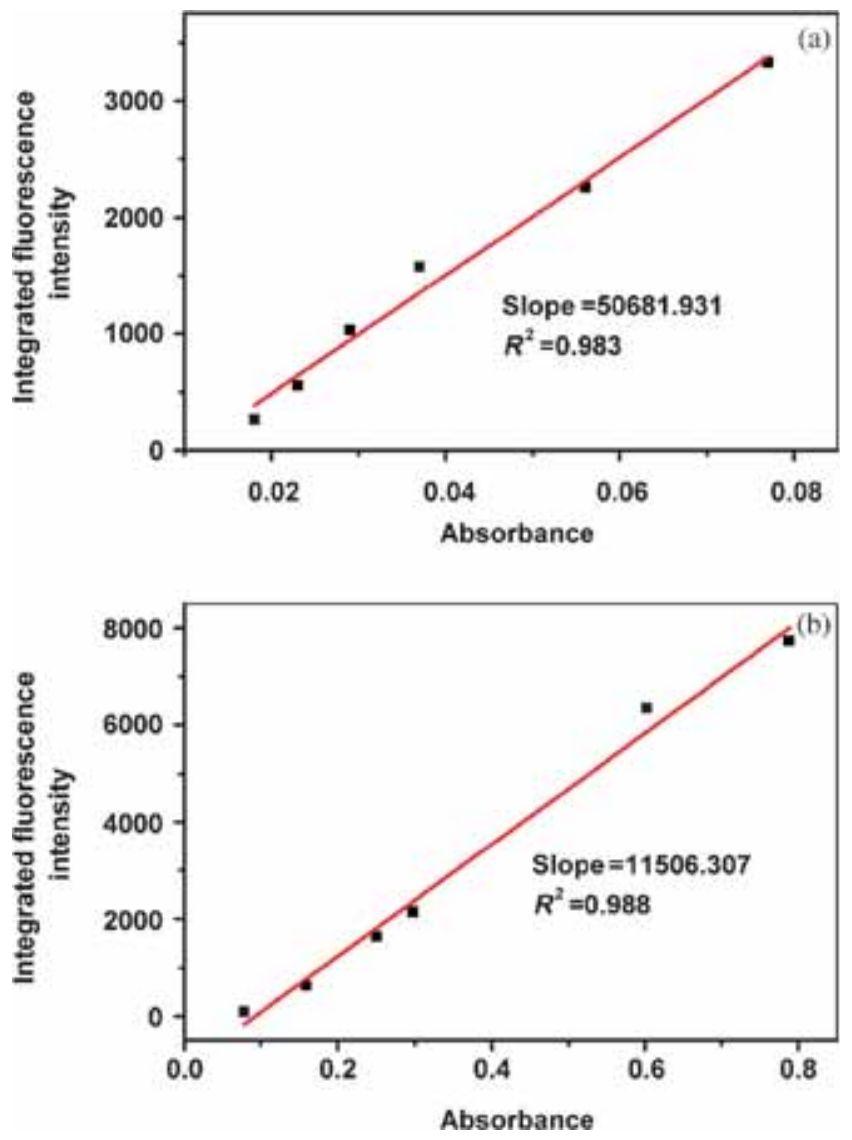

Figure 9. Plot of absorbance against intergrated flouresence intensity of (a) quinine sulphate and (b) ZnO NPs. bonding to oxygen atoms and not $\mathrm{Zn}-\mathrm{C}-\mathrm{O}$ alloys) [71]. In the $\mathrm{O} 1 \mathrm{~s}$ spectrum, the strong peak at $532 \mathrm{eV}$ is attributed to oxygen ions $\left(\mathrm{O}^{2-}\right)$ [42]. It is remarkable to note that the sample is very pure and does not contain any carbon residues.

\subsection{Photocatalytic hydrogen generation}

Hydrogen generation by $\mathrm{ZnO}$ NPs in UV light and visible light is presented in figure 12. It can be observed that $\mathrm{ZnO}$ NPs show 41 and $140 \mu \mathrm{mol} \mathrm{g}^{-1}$ (average of two trials) of hydrogen generation when exposed to UV illumination and visible light illumination, respectively. Janet et al [31] have reported evolution of $35 \mu \mathrm{mol} \mathrm{h}^{-1}(0.1 \mathrm{~g})^{-1}$ hydrogen by $\mathrm{ZnO}$ nanostructures prepared by wet etching method. The particle morphology and size, reduced band gap and emission intensities of $\mathrm{ZnO}$ NPs played a major role in exhibiting this property. The mechanism behind this reaction can be explained as follows [74]: the photoexcited electron formed by the exposure of the semiconductor to light of suitable energy is transferred from the $\mathrm{CB}$ to the adsorbed water molecule, which is reduced to hydrogen atom as follows:

$$
\mathrm{H}_{2} \mathrm{O}+\mathrm{e}^{-} \longrightarrow \mathrm{H}+\mathrm{OH}^{-}
$$

Two such hydrogen atoms combine to form molecular hydrogen. The photocatalytic efficiency of $\mathrm{ZnO}$ is greatly reduced by the photocorrosion process where under irradiated condition the photogenerated holes oxidize the photocatalyst itself, leading to its dissolution [31]. This can be avoided by the use of a sacrificial agent that combines with the generated holes, protects the photocatalyst and reduces recombination. Sacrificial agents are reported to enhance photocatalytic activity hundred times [75].

A hole in the VB caused by the movement of electron to $\mathrm{CB}$ is compensated by an electron from the sacrificial donor (D), in the present study, ethanol, as given by equation (7). A schematic representation of these reactions is depicted in figure 13.

$$
\mathrm{h}^{+}+\mathrm{D} \longrightarrow \mathrm{D}^{+}
$$

The thermodynamic feasibility of this reaction is controlled by more negative potential of electrons in the conduction
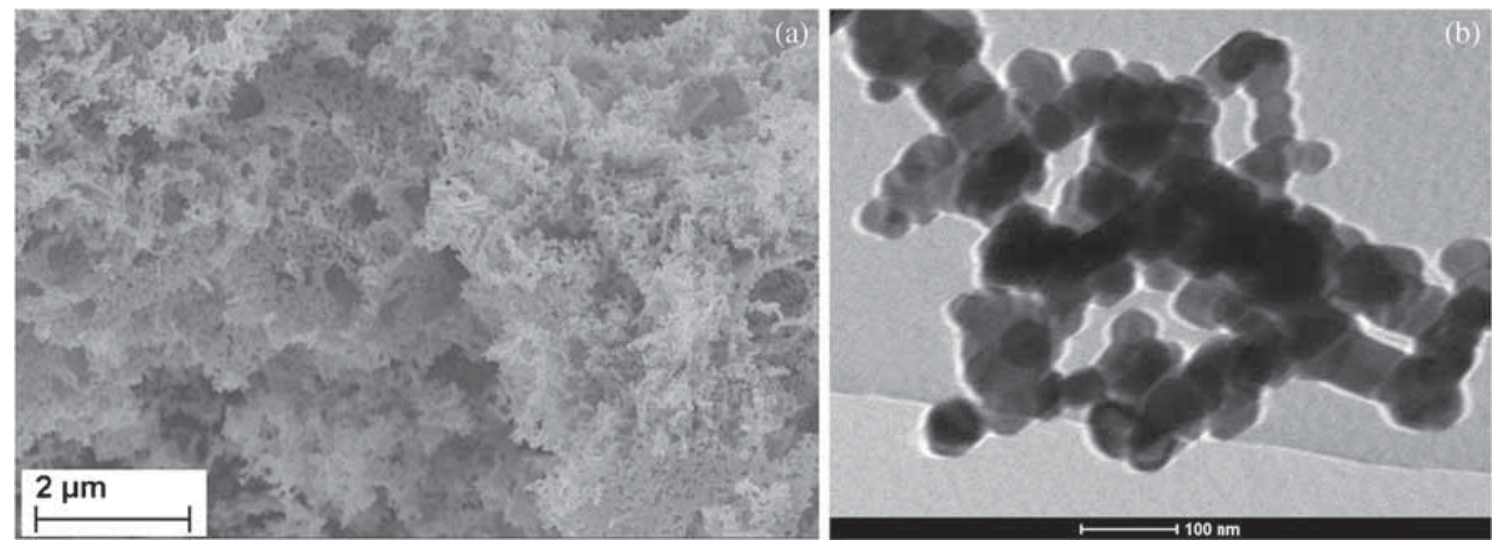

Figure 10. SEM and TEM micrographs of $\mathrm{ZnO}$ NPs. 

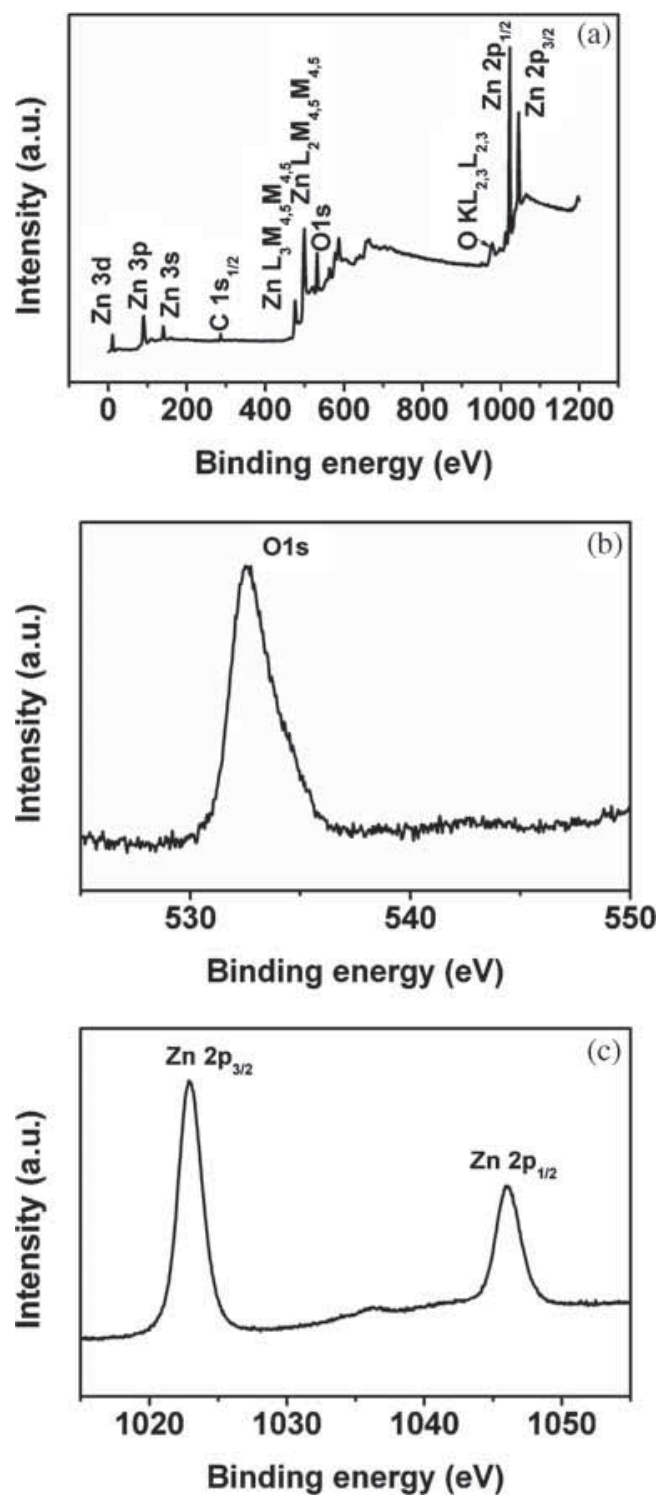

Figure 11. XPS spectrum of $\mathrm{ZnO}$ NPs.

band compared to the potential of the hydrogen electrode and more positive potential of the holes in the valence band compared to the oxidation potential of the donor. The photogenerated hydrogen and oxygen can recombine to form water again on the surface of the photocatalyst and this is called 'surface back reaction' (SBR). SBR has a negative influence on hydrogen production as it reduces the amount of hydrogen generated from the photocatalyst. SBR can be minimized in two ways: in the first approach, like the one done in this work, suitable sacrificial agents that are electron donors and acceptors are added to the photocatalytic environment. This becomes the major surface reaction and reduces recombination of oxygen and hydrogen. The second approach is the separation of photoactive sites on the surface of the photocatalyst [70]. This factor depends upon the surface properties and morphology of the photocatalyst, which has been discussed, at length, elsewhere in the article. The rate of

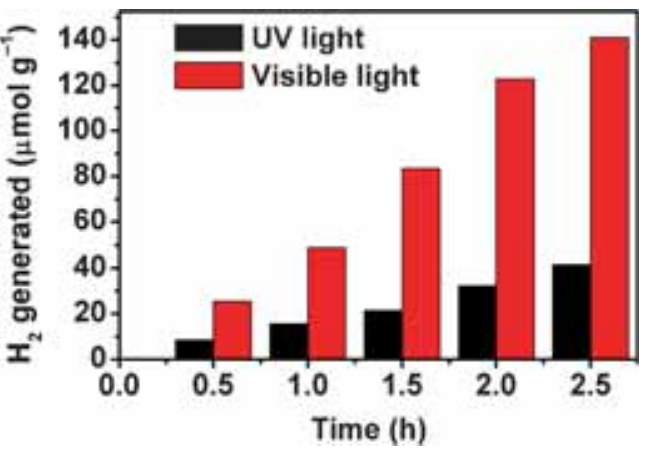

Figure 12. Photocatalytic hydrogen generation by ZnO NPs.

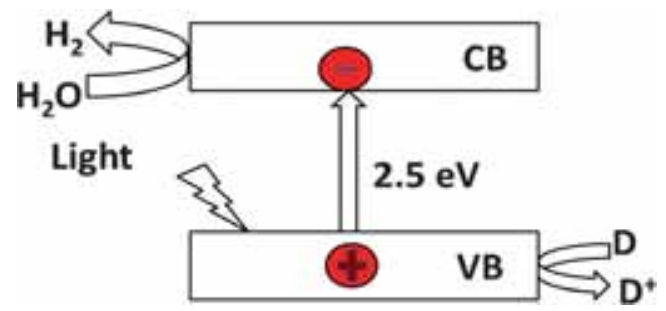

Figure 13. Schematic representation of hydrogen generation reaction mechanism.

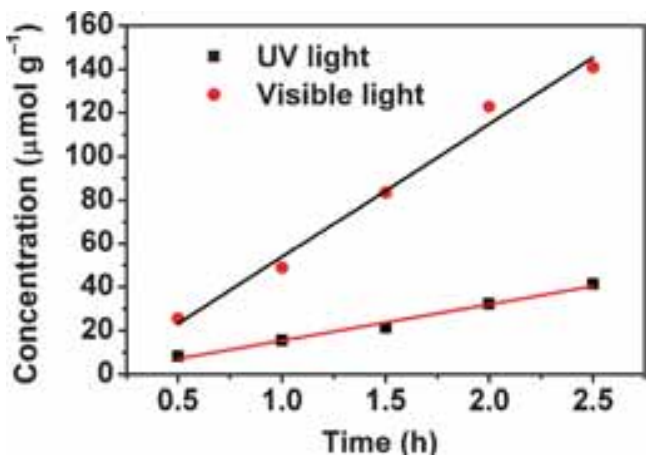

Figure 14. Zero order kinetics of hydrogen generation.

photocatalytic hydrogen generation follows zero order kinetics; the amount of hydrogen generated is plotted as a function of time as seen in figure 14 . The plots were fitted to a straight line with the correlation constant $\left(R^{2}\right)$ being 0.984 and 0.983 for UV and visible light, respectively.

\section{Conclusion}

ZnO NPs were prepared by a simple gel combustion method using bio-fuel, cassava starch. The ZnO NPs were of hexagonal wurtzite symmetry with a band gap of $2.5 \mathrm{eV}$. The XPS and Raman spectra confirmed the purity of the sample. The particle size was around $45 \mathrm{~nm}$ and they were of loop and chain morphology. The PL spectrum showed reduced emission intensity due to oxygen excess defect introduced into the lattice during synthesis and negligible vacancy defects (recombination centres), making ZnO NPs a promising 
photocatalyst; 41 and $140 \mu \mathrm{mol} \mathrm{g}^{-1}$ of hydrogen were produced, respectively, under UV and visible light illumination.

\section{Acknowledgement}

T N Ravishankar acknowledges CNPq-TWAS for the fellowship. The authors acknowledge Dr K Manjunath, Jawaharlal Nehru Centre for Advanced Scientific Research, for XPS and Raman spectra and Ms K R Chethana, Jain University, and Ms B Hemavathi, Jain University, for their help in carrying out quantum yield experiment.

\section{Electronic Supplementary Material}

Supplementary Material pertaining to this article is available on the Bulletin of Materials Science website (www.ias.ac.in/ matersci).

\section{References}

[1] Bunn C W 1935 Proc. Phys. Soc. 47835

[2] Coleman V A and Jagadish C 2006 Basic properties and applications of $\mathrm{ZnO}$ in: Zinc oxide bulk, thin films and nanostructures (Amsterdam: Elsevier) p 1

[3] Thomas D G 1960 J. Phys. Chem. Solids 1586

[4] Ramasami A K, Naika H R, Nagabhushana H, Ramakrishnappa T, Balakrishna G R and Nagaraju G 2015 Mater. Charact. 99266

[5] Nickel N H and Terukov E 2005 (eds) Zinc oxide-a material for micro- and optoelectronic applications (Netherlands: Springer)

[6] Huang J, Yin Z and Zheng Q 2011 Energy Environ. Sci. 4 3861

[7] Manjunath K, Lingaraju K, Kumar D, Nagabhushan H, Samrat D, Reddy V, Dupont J, Ramakrishnappa T and Nagaraju G 2015 Int. J. Nanosci. 141550005

[8] Ramimoghadam D, Hussein M Z B and Yap Y H T 2013 Chem. Cent. 7136

[9] Meulenkamp E A 1998 J. Phys. Chem. B 1025566

[10] Ha T T, Canh T D and Tuyen N V 2013 ISRN Nanotechnol. 2013 Article ID 497873

[11] Singh R P, Shukla V K, Yadav R S, Sharma P K, Singh P K and Pandey A C 2011 Adv. Mater. Lett. 2313

[12] Ramimoghadam D, Hussein M Z B and Yap Y H T 2013 Chemistry Cent. 771

[13] Zhang G, Shen X and Yang Y 2011 J. Phys. Chem. C 115 7145

[14] Taubert A and Wegner G 2012 J. Mater. Chem. 12805

[15] Riahi-Noori N, Sarraf-Mamoory R, Alizadeh $P$ and Mehdikhani A 2008 J. Ceram. Process. Res. 9246

[16] Gegova R, Dimitriev Y and Bachvarova-Nedelcheva A 2013 J. Chem. Technol. Metall. 48147

[17] Patil K C et al 2013 Combustion synthesis, novel synthesis and characterization of nanostructured materials (Heidelberg: Springer)
[18] Welsch R, Arango J, Bar C, Salazar B, Babili S A, Beltran J, Chavarriaga P, Ceballos H, Tohme J and Bayer P 2013 Plant Cell 223348

[19] Cock J H 1995 Cassava: new potential for a neglected crop (London: Weatfield)

[20] Best R and Henry G 1992 in: W M Roca and T M Thro (eds) Report of the first meeting of the International Network for Cassava Genetic Resources (Columbia, California: Centro Internacional de Agricultura Tropical) p 3

[21] Mann C 1997 Science 2771038

[22] Mishra S and Rai T 2006 Food Hydrocolloid. 20557

[23] Liao C-H, Huang C-W and Wu J C S 2012 Catalysts 2490

[24] Steinfeld A 2002 Int. J. Hydrogen Energy 27611

[25] Licht S 2005 Chem. Commun. 374635

[26] Fujishima A and Honda K 1972 Nature 23837

[27] Nagaraju G, Ravishankar T N, Manjunath K, Sarkar S, Nagabhushana H, Gonclaves R and Dupont J 2013 Mater. Lett. 10927

[28] Laveena P D'Souza, Sindu Shree and Geetha R Balakrishna 2013 Ind. Eng. Chem. Res. 5216162

[29] Ravishankar T N, Ramakrishnappa T, Nagabhushana H, Souza V S, Dupont J and Nagaraju G 2015 New J. Chem. 39 1421

[30] Hussein A M, Mohaney L, Peng R, Kibombo H, Wu C M, Koodali R T and Shende R 2013 J. Renew. Sustain. Energy 51

[31] Janet C, Navaladian S, Viswanathan B, Varadarajan T K and Vishwanath R P 2010 J. Phys. Chem. C 1142622

[32] Wang X and Yao X 2014 Carbon 77667

[33] Peng T-Y, Liv H-J, Zeng P and Zang X-H 2011 Chin. J. Chem. Phys. 24464

[34] Jagadeesh A, Rattan $T$ M, Muralikrishna $M$ and Venkataramaiah K 2014 Mater. Lett. 121133

[35] Tulyathan V, Chimchom K, Ratanathammapan K, Pewlong C and Navankasattusas S 2006 J. Sci. Res. Chula Univ. 114

[36] Langford J I, Cernik R J and Louer D 1991 J. Appl. Crystallogr. 24913

[37] Kumar P M, Badrinarayanan S and Satry M 2000 Thin Solid Films $\mathbf{3 5 8} 122$

[38] He G, Fang Q, Zhu L, Liu M and Zhang L 2004 Chem. Phys. Lett. 395259

[39] Phattalung S N, Smith M F, Kim K, Du M-H, Wei S-H, Zhang S B and Limpijumnong S 2006 Phys Rev. B: Condens. Matter 731252051

[40] Etacheri V, Seery M K, Hinder S J and Pillai S C 2011 Adv. Funct. Mater. 213744

[41] Mote V D, Huse V R and Dole B N 2012 World J. Condens. Matter Phys. 2208

[42] Sivasubramanian D, Ponnusamy R and Gandhiraj V 2015 Mater. Chem. Phys. 15993

[43] Zak A K, Abrishami M E, Majid W H A, Yousefi R and Hosseini S M 2011 Ceram. Int. 37393

[44] Zak A K, Razali R, Majid W H A and Darroudi M 2011 Int. J. Nanomed. 61399

[45] Zhao Y, Eley C, Hu J, Ford T S, Ye L, He H and Tsang S C E 2012 Angew. Chem. 1241

[46] Pal B, Dhara S, Giri P K and Sarkar D 2014 J. Alloys Compd. 615378 
[47] Shwetharani R, Jyothi M S, Laveena P D and Balakrishna R G 2014 Photochem. Photobiol. 901099

[48] Swetha S and Balakrishna G R 2011 Chin. J. Catal. 32789

[49] Minchitha K U and Balakrishna G R 2012 Mater. Chem. Phys. 136720

[50] Baruah S, Rafique R F and Dutta J 2008 Nano: Brief Rep. Rev. 3399

[51] Machlin E S 2006 Materials science in microelectronics: the effect of structure on properties in thin films (Oxford: Elsevier)

[52] Wunderlich W, Miao L, Tanemura M, Tanemura S, Jin P, Kaneko K, Terai A, Nabatova-Gablin N and Belkada R 2009 Int. J. Nanosci. 3439

[53] Klubnuan S, Suwanboon S and Amornpitoksuk P 2016 Opt. Mater. 53134

[54] Urbach F 1953 Phys. Rev. 92134

[55] Oleary S K, Zukotynski S and Perz J M 1997 J. Non-Cryst. Solids 210249

[56] Mahmud W E and Harbi T A 2011 J. Crystal Growth 32752

[57] Wang S, Xia G, Shao J and Fan Z 2006 J. Alloys Compd. 424 304

[58] Lee C-T 2010 Materials 32218

[59] Djurisic A B, Leung Y H, Tam K H, Hsu Y F, Ding L, Ge W K, Zhong Y C, Wong K S, Chan W K, Tam T L, Cheah K W, Kwok W M and Philips D L 2007 Nanotechnology 18095702

[60] Cho S, Ma J, Kim Y, Sun Y, Wong G K L and Ketterson J B 1999 Appl. Phys. Lett. 752761

[61] Bagnall D M, Chen Y F, Shen M Y, Zhu Z, Goto T and Yao T 1998 J. Crystal Growth 184-185 605
[62] Xiao H, Sun M, Li C, Yang D, Han B and He S 2008 Nucl. Instrum. Methods Phys. Res. B 2663275

[63] Patwari G, Bodo B J, Singha R and Kalita P K 2013 Res. J. Chem. Sci. 345

[64] Kohan A F, Ceder G and Morgan D 2000 Phys. Rev. B 615019

[65] Jeong S H, Kim B-S and Lee B-T 2003 Appl. Phys. Lett. 82 2625

[66] Lv J, Li C and BelBruno J J 2013 CrystEngComm 155620

[67] Anpo M, Aikawa N and Kubokawa Y 1985 J. Phys. Chem. 89 5017

[68] Kong Y C, Yu D P, Zhang B, Fang W and Feng S Q 2001 Appl. Phys. Lett. 78407

[69] Etacheri V, Roshan R and Kumar V 2012 ACS Appl. Mater. Interfaces 42717

[70] Chen X, Shen S, Guo L and Mao S S 2010 Chem. Rev. 110 6503

[71] Ravishankar T N, Manjunatha K, Ramakrishnappa T, Nagaraju G, Dhanith Kumar S, Sarakar S, Anandakumar B S, Chandrappa G T, Reddy Viswanath and Dupont J 2014 Mater. Sci. Semicond. Process. 267

[72] Balazs N, Sranko D F, Dombi A, Sipos P and Mogyorosi K 2010 Appl. Catal. B: Environ. 96569

[73] Jing D, Zhang Y and Guo L 2005 Chem. Phys. Lett. 41574

[74] Stroyuk A L, Kryukov A I, Kuchmii S Y and Pokhodenko V D 2009 Theor. Exp. Chem. 45209

[75] Ravelli D, Dondli D, Fagnoni M and Albini A 2009 Chem. Soc. Rev. 381999 